\title{
Excision of furuncular myiasis larvae using a punch: a simple, practical and aesthetic method ${ }^{*}$
}

\author{
Gianne Pascoal ${ }^{1}$ \\ Rosana Rocon Siqueira ${ }^{1}$ \\ Marcelino Pereira Martins Neto ${ }^{1,2}$
}

\author{
Fernanda Queiroz de Oliveira ${ }^{1}$ \\ Maria Gabriela Araújo Lopes ${ }^{1}$ \\ Aloísio Carlos Couri Gamonal ${ }^{1,2,3}$
}

DOI: http:/ / dx.doi.org/10.1590/abd1806-4841.20163999

\begin{abstract}
Myiasis refers to Diptera larvae infesting vertebrate animals. There are two forms of the disease: primary and secondary. In primary myiasis, fly larvae invade and develop in healthy tissue; in secondary myiasis, flies lay their eggs in skin ulcerations, and the larvae develop in tissue necrosis products. Furuncular myiasis is a type of primary myiasis. Treatment for it consists of techniques such as the production of localized hypoxia to force the emergence of the larvae, and mechanical or surgical removal of the maggots. These techniques, however, are painful and often unsuccessful. We propose a new technique for extraction of myiasis larvae, which might facilitate the surgical procedure and constitute a virtually painless and aesthetic option for the patient.
\end{abstract}

Keywords: Diptera; Hypodermyiasis; Myiasis

\section{INTRODUCTION}

Myiasis refers to Diptera larvae infesting vertebrate animals. It affects mainly developing countries and is the fourth most common travel-related disease in places where it is not endemic. ${ }^{1}$ There are two forms of myiasis: primary and secondary. In primary myiasis, fly larvae invade and develop in healthy tissue. They are thus obligate parasites at this stage. In secondary myiasis, flies lay their eggs in cutaneous or mucous ulcerations, and the larvae develop in tissue necrosis products. In these cases they are occasional parasites. ${ }^{2}$ The disease causes feelings of disgust and discomfort to the patient, and the extraction of the larvae presents a technical difficulty to health professionals. The risk factors for myiasis include low economic status and precarious hygiene standards. ${ }^{3}$ Pruritus, pain, and movement sensation are the most commonly reported symptoms, followed by serous output from small ori- fices. ${ }^{4}$ Furuncular myiasis (boil-like myiasis) - the form analyzed in this article - is the most common type of primary myiasis, and its causative agent in the Americas is Dermatobia hominis (D. hominis). In Brazil, it is known as "berne" . Diagnosis is based on history, especially in endemic regions. In case of doubt, dermoscopy, ultrasound and MRI can help make the diagnosis. ${ }^{6}$ Treatment for furuncular myiasis consists of three techniques: application of toxic substances to the eggs and larvae; methods producing localized hypoxia to force emergence of the larvae; and mechanical or surgical debridement. ${ }^{7,8}$ We propose here a new technique for treating furuncular myiasis using a skin trephine ("punch"). This technique might facilitate the surgical procedure and constitute a virtually painless and aesthetic option for the patient.

Received on 03.09.2014

Approved by the Advisory Board and accepted for publication on 03.12.2014

Study conducted at the Center for Research in Dermatology - University Hospital, Federal University of Juiz de Fora (Nupede-HU-CAS- UFJF) - Juiz de Fora (MG), Brazil.

Financial Support: None.

Conflict of Interest: None.

Universidade Federal de Juiz de Fora (UFJF) - Juiz de Fora (MG), Brazil.

Faculdade Presidente Antônio Carlos (UNIPAC) - Juiz de Fora (MG), Brazil.

Faculdade de Ciências Médicas e da Saúde de Juiz de Fora (Suprema) - Juiz de Fora (MG), Brazil.

(C)2016 by Anais Brasileiros de Dermatologia 


\section{CASE REPORT}

We describe two cases of furuncular myiasis. Our patients were both female and in their third decade of life. One lived in the rural area of Muriaé, MG, and the other had a history of travel to the same rural area two weeks before the onset of symptoms. Both patients complained of having pain in the nodular lesion, serous drainage and movement sensation in the left breast and in the left mandibular region, respectively, for about two weeks. The diagnosis of furuncular myiasis in both cases was based on clinical and epidemiological data. We performed antisepsis of the surgical site, local an- esthesia with lidocaine (infiltrating the periphery of the lesion in order to prevent puncturing the larvae) and created an orifice using punch 4 (Figure 1A). Detachment of the incised skin fragment was not carried out, in order to keep the pedicle intact and avoid tissue necrosis (Figure 1B). Next, we lightly compressed the skin and the larva came out of the orifice in its entirety. The incised skin fragment was then relocated and an occlusive dressing was applied to the wound in order to permit proper healing and obtain an aesthetic result (Figures 1C, 1D, 2A, 2B and 2C).
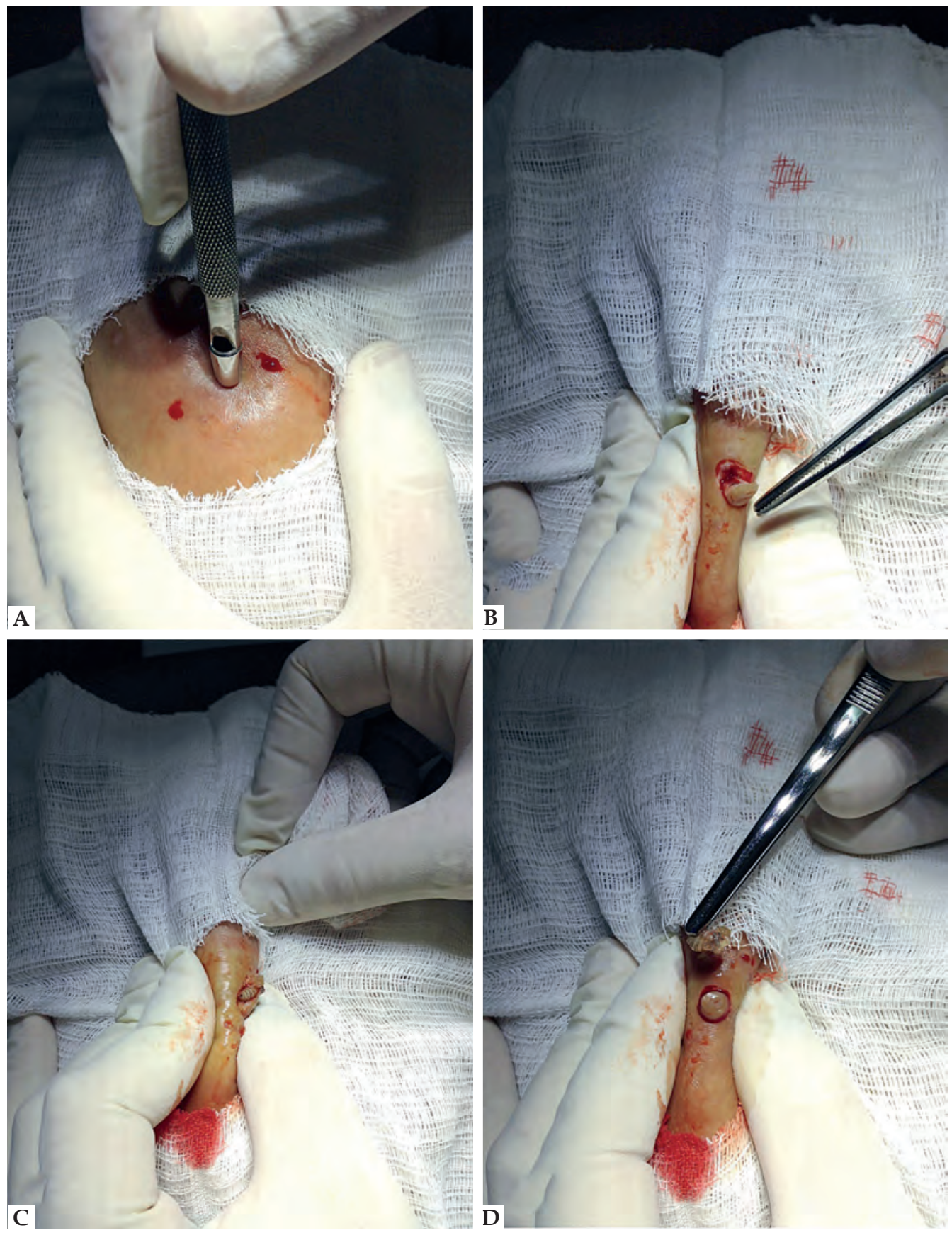

Figure 1:

Furuncular myiasis of breast. A: After performing antisepsis and perilesional anesthesia, the fragment was cut using the punch. B: Skin fragment cut by the punch. The pedicle was kept intact to allow for the posterior relocation of the fragment. C: Delicate compression to extract the larva through the orifice. Visualization of black anchoring spikes. D: hominis larva and relocation of the cut fragment 


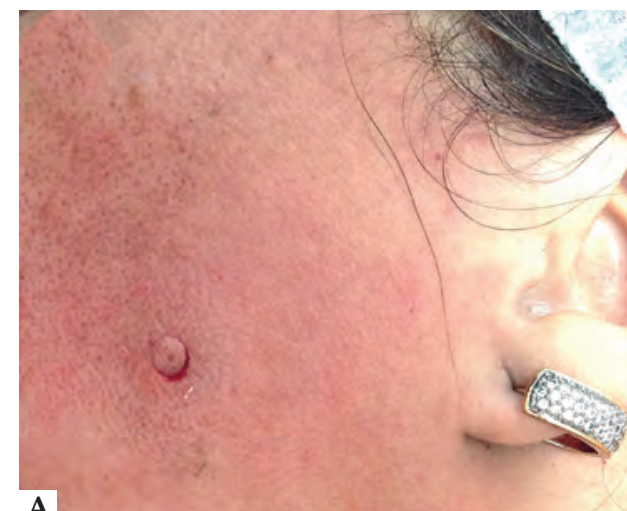

A
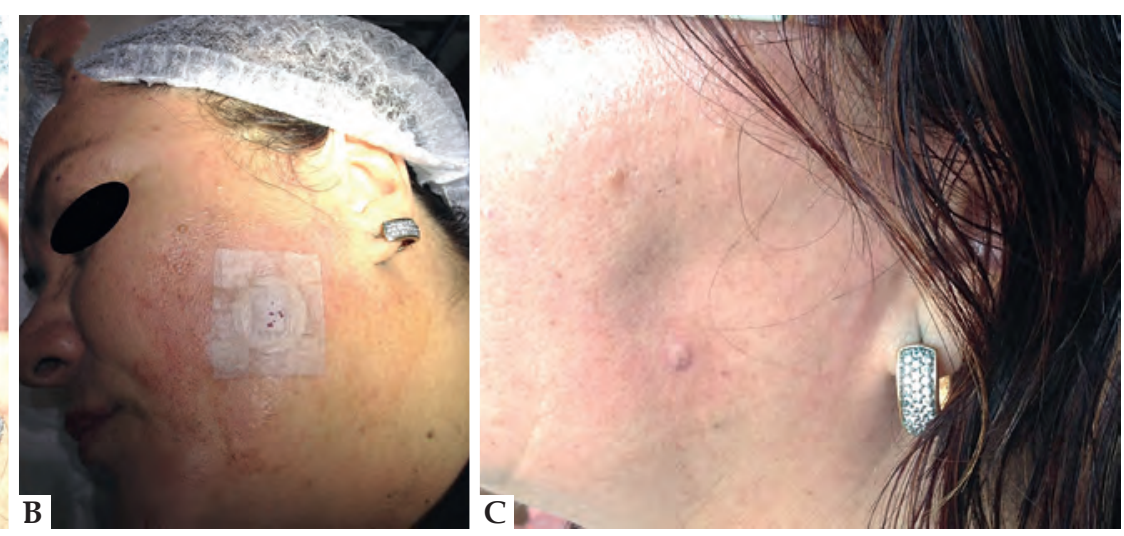

Figure 2: Treatment of furuncular myiasis of face using a punch. A: Creation of the orifice after antisepsis and local anesthesia. B: After extraction of the larva and relocation of the skin fragment cut using the punch, an occlusive dressing was applied to the wound to permit proper healing. C: Aesthetic result after 14 days

\section{DISCUSSION}

Myiasis is the invasion of dead or necrotic body tissues by Diptera larvae. The furuncular form of the disease presents as a pruriginous, erythematous nodule, similar to an insect bite, which drains serous fluid from a central orifice, and is associated with pain and a movement sensation. In the life cycle of $\mathrm{D}$. hominis, the female deposits her eggs onto mosquitoes that feed on mammalian blood. The larva then penetrates the skin and reaches the subcutaneous tissue, where it remains for about 100 days. The maggot exits the host through the central orifice, falls to the ground, and pupates during the next 2-3 weeks. D. hominis emerges as an adult and lives for 8-9 days, during which time it lays eggs on mosquitoes, completing the cycle. ${ }^{9}$ Although it only remains in the host for 100 days, the majority of affected persons choose to have the larva removed as soon as the disease is diagnosed. There are several extraction techniques, but the ideal technique is the one that is practical, less painful and leads to less risk of secondary infection. The currently most widely used techniques for myiasis treatment are manual compression, larva asphyxiation by occlusion, and surgical removal with a scalpel. They all have some drawback: technical difficulty, pain, rupture of the larva or unaesthetic scars. Compression causes discomfort and pain to the patient, and is difficult to perform in areas with little folding such as the scalp or in individuals in certain age groups such as children or older adults. Furthermore, the circumference of the larva and its spikes, which anchor into the skin, hinder removal by lateral compression. Occlusion has been reported using mineral oil, petroleum jelly, bacon, adhesive tapes, enamel, glue and chewing gum. ${ }^{10}$ These alternatives, however, may be unsuccessful and elicit foreign body granulomatous reactions if the larva remains in the subcutaneous tissue instead of exiting through the orifice. Surgical removal with a scalpel is an often unnecessary invasive technique. Moreover, it is contraindicated in cases with cellulitis and often lacerates the larva, causing local inflammation. The punch is an instrument composed of a circular cutting blade attached to a rod. The use of punch to create an orifice that allows the extraction of the larva makes (delicate) lateral compression possible without causing major trauma to the skin. The larva is removed in its entirety, thereby minimizing the potential of an inflammatory response caused by its fragmentation. Besides, it is a less painful procedure, because it is performed with local anesthesia. Furthermore, this surgical extraction method does not remove the skin fragment cut by the punch, as it is used to cover the cavity created by it. This allows for a more aesthetic and almost imperceptible healing of delicate body areas such as the face, because there is no need for suturing of the incision. Treatment of furuncular myiasis with punch excision of the larvae is a simple and practical technique, and, in addition to generating excellent cosmetic results, causes less discomfort to the patient. $]$ 


\section{REFERENCES}

1. Caumes E, Carrière J, Guermonprez G, Bricaire F, Danis M, Gentilini M. Dermatoses associated with travel to tropical countries: a prospective study of the diagnosis and management of 269 patients presenting to a tropical disease unit. Clin Infect Dis. 1995;20:542-8.

2. Goddard J. Flies whose maggots cause myiasis in humans. In: Goddard J. Physician's Guide to Arthropods of Medical Importance. 2nd ed. Florida: CRC Press; 1996. p.169-187.

3. Marquez AT, Mattos MD, Nascimento SB. Myiasis associated with some socioeconomic factors in five urban areas of the State of Rio de Janeiro Rev Soc Bras Med Trop. 2007;40:175-80.

4. Mahal JJ, Sperling JD. Furuncular myiasis from Dermatobia hominus: a case of human botfly infestation. J Emerg Med. 2012;43:618-21.

5. Hunter JM. Bot-fly maggot infestation in Latin America. Geogr Rev 1990;80:382-9.

6. Bakos RM, Bakos L. Dermoscopic diagnosis of furuncular myiasis. Arch Dermatol. 2007;143:123-4.

7. Francesconi F, Lupi O. Myiasis. In Tyring SK, Lupi O, Hengge UR, editors. Tropical dermatology. Philadelphia, PA: Elsevier; 2006: p 232-239.

8. Brent AJ, Hay D, Conlon CP. Souvenirs to make your skin crawl. Lancet Infect Dis. 2008;8:524.

9. Mathieu ME, Wilson BB. Myiasis. In: Mandell G, Bennett E, Dolin R, eds. Principles and practice of infectious diseases. 5th ed. New York: Churchill-Livingstone; 2000. p.2976-9

10. Brewer TF, Wilson ME, Gonzalez E, Felsenstein D. Bacon therapy and furuncular myiasis. JAMA. 1993;270:2087-8.
MAILING ADDRESS:

Gianne Pascoal

Rua Túlio Sérgio, 75, apto 703, setor Nova Aurora 75522-190 - Itumbiara - Goiás

Brazil

E-mail: gianne_pascoal@hotmail.com

How to cite this article: Pascoal G, de Oliveira FQ, Siqueira RR, Lopes MGA, Martins Neto MP, Gamonal ACC. (Treatment of furuncular myiasis using a punch: a simple, practical and aesthetic method). An Bras Dermatol. 2016;91(3):358-61. 